\title{
LA "NOCHE MEXICANA" COMO PARTE DE LOS FESTEJOS DE CELEBRACIÓN DE LA INDEPENDENCIA DE 1921 María de las Nieves Rodriguez*
}

RESUMEN: Como celebración del Centenario de Consumación de la Independencia de 1921, el gobierno de Álvaro Obregón -emulando al porfirista- llevó a cabo distintios festejos, entre los cuales destaca la "Noche mexicana", que ensalza valores nacionalistas e indígenas.

yose

ABSTRACT: In 1921, Álvaro Obregón's government -following that of Porfirio Díaz- held various festivities for the centennial of the Consummation of Independence, among which the most notable is the "Mexican Night" celebrating nationalistic and indigenous values.

PALABRAS ClAVE: Celebración de Independencia de 1921, Noche mexicana, Álvaro Obregón, Método de dibujo, Adolfo Best Maugard, Chapultepec.

KEY WORDS: 1921 Independence Celebration, Mexican Night, Álvaro Obregón, A Method of Creative Design, Adolfo Best Maugard, Chapultepec.

RECEPCIÓN: 4 de septiembre de 2012.

APROBACIÓN: 24 de enero de 2013.

* Maestra en Historia del Arte, Universidad Nacional Autónoma de México. 
CITAM Derechos Reservados.

La reproducción total o parcial de este artículo se podrá hacer si el ITAM otorga la autorización previamente por escrito. 


\title{
LA "NOCHE MEXICANA" COMO PARTE DE LOS FESTEJOS DE CELEBRACIÓN DE LA INDEPENDENCIA DE 1921
}

\begin{abstract}
Poco se han estudiado las representaciones gráficas relativas a la Celebración de la Consumación del Centenario de la Independencia de 1921 si se toma en cuenta la escasa difusión de las reproducciones fotográficas que de tal acontecimiento se han divulgado. Las fotografías, como recuerdos inmemoriales de un pasado que no quiere pasar, son la iconografía atemporal que crea el imaginario nacional donde converge no sólo la Historia, sino también los distintos tiempos históricos, las generaciones e, incluso, la historia oral de aquellos que aún pueden contarla y hacer aportaciones a la misma. Así, la representación del pueblo ya no se reproduce en el imaginario de la Historia, sino de tantas historias que, juntas, pueden hacerla grande y unificada. En tiempos convulsos, revolucionarios y de paz a medias, sólo las historias muestran lo que la Historia ha contado a la postre, lo que se ha reedificado y analizado como la narración histórica del pasado nacional, como la memoria cautiva de la Historia mexicana.

Así, en 1921 se intentó recuperar esa memoria con las celebraciones centenarias para las cuales se organizaron -como ocurrió con la celebración que el Gobierno porfirista hizo en 1910- en un Comité ejecutivo que estaba conformado por Emiliano López Figueroa como Presidente, Juan de Dios Bojórquez como Vice-Presidente, Martín Luis Guzmán como Secretario y Carlos Argüelles como Tesorero. ${ }^{1}$ Juntos

${ }^{1}$ Cfr. Programa Oficial de las Fiestas del Centenario de la Consumación de la Independencia de México, 1921, México, La Helvetia.
\end{abstract}


realizaron el Programa oficial de los festejos que, presididos por el General Obregón, se llevaron a cabo durante el mes de septiembre de ese mismo año. Cabe decir que, a diferencia de las fiestas de 1910, la conmemoración se socializó de tal modo que instituciones privadas como el periódico El Universal, la Compañía Independiente de Luz y Fuerza, la Universidad Nacional de México o el diario Excélsior, entre otros, participaron de los acontecimientos realizando - de modo independiente- fiestas y actos de carácter popular a los que acudió la población. Estos actos ofrecieron, para el deleite de sus asistentes, desde un desfile de carros alegóricos hasta un festival floral en Xochimilco, pasando por concursos de corte literario o musicales, de donde se eligió el himno del Centenario. Igualmente, se llevó a cabo la inauguración del conjunto de la Ciudadela, en Teotihuacán, en el que el mismo Manuel Gamio fungió como "guía" durante todo el recorrido. En suma, se trató de un derroche nacionalista que mostró la magnificencia y el resurgimiento de la patria tras el movimiento revolucionario que había legitimado nuevamente el poder en el pueblo mexicano -al igual que en la gesta insurgente. Así, las alusiones al y a lo indígena fueron de vital importancia para el desarrollo artístico-cultural y filosófico del momento.

Ejemplo de esto fue que "la India Bonita" (María Bibiana Uribe) -producto de un concurso de El Universal donde se exaltaba la belleza indígena $-{ }^{2}$ desfilara en un carro alegórico donde se contraponían las imágenes del indígena del pasado con la del actual idealizado. La India Bonita, convertida entonces en icono de la belleza nacional, fue homenajeada en varias ocasiones por la corte gubernamental y el pueblo. ${ }^{3}$ Otro ejemplo, la exposición itinerante de arte popular organizada por Gerardo Murillo -doctor Atl-, Jorge Enciso y Roberto Montenegro ${ }^{4}$ con el fin de rescatar y, por ende, exaltar la artesanía popular mexicana (con este material el doctor Atl publicó en 1922 Las artes populares en México); celebración que, de modo itinerante, viajó a Italia, Bélgica y Brasil.

${ }^{2}$ Ricardo Pérez Montfort, Estampas de nacionalismo cultural mexicano. Ensayos sobre cultura popular y nacionalismo, México, CIESAS, 2003, p. 176.

3 "La India Bonita será recibida hoy en el Teatro Lírico" en El Universal, 1 de septiembre de 1921, México, p. 1.

${ }^{4}$ Cfr. S. Suárez Longoria, "La exposición de arte popular” en Azulejos, octubre de 1921, México, pp. 28-30. 
La celebración de 1921 una celebración colectiva ${ }^{5}$ que abarcó, incluso, los estratos más pobres de la sociedad, disponiendo para ellos repartos de comida, de ropa y hasta un paseo en auto por la ciudad para que pudieran participar, igualmente, de la modernidad de un Estado ${ }^{6}$ incipiente que Álvaro Obregón quiso celebrar de modo “esencialmente popular", 7 con el fin de potenciar la unión entre todos los habitantes y de iniciar el proceso de identificación por medio de ese sistema codificado de símbolos que logró permear el sentimiento nacionalista en los mismos. El Estado que se abocó a la tarea de "inventar la nación"8 se representó como una comunidad fraternal con un pasado común a todo el pueblo mexicano y un lenguaje simbólico con el que se pudo identificar (la Bandera, el Himno nacional, los murales o la lengua ${ }^{9}$ y por la cual fue rescatada la población indígena para insertarla a la ya estipulada cultura "nacional". ${ }^{10}$

Las fiestas, de este modo, se desarrollaron bajo una óptica patriótica que albergó acontecimientos de diversa índole. Los embajadores,

5 "El Pueblo tendrá acceso a todas las fiestas del Centenario" en El Universal, 2 de junio de 1921, México, p. 1.

${ }^{6}$ El Comité, que pidió opinión incluso a varios directores de prensa nacional, hubo de tener en cuenta ese aspecto para la organización de los festejos en los que "estará representado lo popular con sus ruidosos entusiasmos; lo exquisito, con los refinamientos del arte y de la distinción aristocrática; $y$, para que los mexicanos todos participen en las grandes solemnidades conmemorativas -ya que para todos, también, se realizó la Independencia- el Comité solicitará el concurso de las diferentes agrupaciones sociales, políticas y religiosas", Clementina Díaz y de Ovando, "Las Fiestas del "Año del Centenario": 1921", en México: independencia y soberanía, 1996, México, Secretaría de Gobernación, Archivo General de la Nación, p. 110.

7 "Serán populares las fiestas del Centenario" en El Universal, 15 de mayo de 1921, México.

${ }^{8}$ Cfr. Benedict Anderson, Comunidades imaginadas. Reflexiones sobre el origen y la difusión del nacionalismo, 1993, México, Fondo de Cultura Económica.

${ }^{9}$ Estos símbolos tienen un carácter determinante en la sociedad mediante una reglamentación que todos cumplen a través de ciertos rituales colectivos de carácter repetitivo. Con esto lograrán crear un nexo de unión con el pasado que, aunque a veces pueda resultar ficticio, creará y se legitimará invariablemente. En este punto, es conveniente decir que hay que diferenciar "tradición" de "costumbre" porque, aunque estén relacionadas, la "costumbre" tiene un carácter invariable. Para más información véase Eric Hobsbawm y Terence Ranger (eds.), La invención de la tradición, Barcelona, Crítica, 2002.

${ }^{10}$ Así, en este preciso momento aceptaron al indígena, ya no como un ser inferior sin aptitudes, sino como un ser al que el dominio del hombre blanco lo había hecho "inepto" ante su progreso, dejándolo de esta forma a un lado de todo avance civilizatorio y, por ende, desarrollado de un modo desigual y en el atraso. Cfr. Manuel Gamio, Forjando patria, 1960, México, Editorial Porrúa. 
miembros del Cuerpo Diplomático, delegados y el mismo pueblo estaba dividido entre inauguraciones (de calles, escuelas, parques...), desfiles (militar, de carros alegóricos, de jura de la bandera...) y funciones culturales celebradas en el Teatro Iris o en el Arbeu. Los actos fueron estructurados temáticamente por día (dedicados al maestro y al niño, a la colonia alemana o a las comunidades pobres), ofreciendo una cantidad numerosa de eventos a los que acudir a bajo costo, como lo fue la corrida de toros amenizada por Rodolfo Gaona y sufragada por el Estado para que el pueblo pudiera acudir, por un módico precio, portando los trajes de china poblana y de charro que dieron rienda suelta a la forja del estereotipo nacional en las siguientes décadas. La crítica sobrevino en la publicación de algunas notas periodísticas jocosas, como la escrita por Martín Galas en El Demócrata. En su opinión:

Las clases populares están gozando, porque tienen festejos... ¡de vez en cuando!

Y puede darse el gusto de ver zarzuelas

y de oír audiciones... ¡en las plazuelas!

¿No tiene gracia ver cómo se divierte la... "aristocracia"?

Para este chiste, juzgo que lo prudente, sería acallar el hambre de tanta gente a la que van a darle, ¡como regalos! huaraches y "vestidos" de los más malos...

¿Qué caro cuesta a nuestro bajo pueblo cualquiera fiesta...!"11

${ }^{11}$ Véase "Los más grandes festejos 'populares' que registra la Historia. Cómo vio 'Martín Galas', con todo su optimismo, las Fiestas Centenarias, el lujo y el... cinismo" en El Demócrata, 27 de septiembre de 1921, México. 
Como parte de los acontecimientos fue organizada una velada nocturna ${ }^{12}$-conocida como la "Noche Mexicana"- a la cual se invitó a la burguesía selecta del país - que hubo de ir ataviada con traje típicoy que fue amenizada con fuegos pirotécnicos y bailables típicos representativos de distintas provincias de la República, amén de los distintos eventos que en el Bosque de Chapultepec se organizaron para tal efecto: puestos de antojitos mexicanos y aguas frescas, de refrescos, vendedoras de "confetti", etc. Todo ello dispuesto para enfatizar "el más genuino mexicanismo"13 del gobierno obregonista y por ende, de las celebraciones patrias. Para esto se dispusieron, a lo largo de todo el Bosque, "diez pabellones, todos ellos de estilo regional mexicano, representando, unos las industrias artísticas del país; otros, sus momentos históricos más salientes, otros, las bellezas de más renombre con que la naturaleza ha dotado a nuestro suelo", ${ }^{14}$ destacando sobremanera aquel pabellón dedicado a la cerámica del estado de Jalisco -cuyo máximo exponente fue Guadalajara-, el dedicado a la producción cerámica de talavera del estado de Puebla o el dispuesto para exhibir las maravillosas lacas de Michoacán. Sin contar aquellos que albergaron las reproducciones fieles de las ruinas arqueológicas de Mitla o Chichenitzá. De este modo, los asistentes hicieron un recorrido histórico-artístico por todo el país en una noche. Para deleitarlos mientras paseaban, se dispusieron tres escenarios representativos del norte, sur y centro de la República, donde se desarrollaron sucesivos espectáculos de canto, baile y música que hicieron las delicias de los espectadores, sucediéndose en un son constante los yucatecos, los "yaquis", los jarochos,

${ }^{12}$ Para maximizar la seguridad del evento y la buena disposición en los distintos pabellones situados a lo largo del Bosque de Chapultepec, la Cruz Roja y Blanca Mexicana -amén de otras instituciones benéficas-se encargaron de proveer algunos de los servicios que se darían en el festejo. Para tal efecto, se reunirían "la señora doña Dolores Rubín de Pesado, presidente de la Comisión de Festejos de la Cruz Roja, las señoritas Guadalupe Aspe y María Luisa de la Torre, y el señor licenciado Manuel J. Sierra, en representación del Comité Ejecutivo del Centenario" con el fin de determinar las acciones que tomarían cada quien en el evento. Así, las damas se encargaron de los puestos donde no faltaron las decoraciones tradicionales y las vendedoras que, ataviadas con sus trajes típicos, atendían a los visitantes y vendían sus productos en loza típica de cerámica. Cfr. "La Noche Mexicana en el Bosque de Chapultepec" en El Universal, 6 de septiembre de 1921, p. 6.

${ }_{13}$ "La Noche Mexicana en los Lagos del Bosque" en Excélsior, 21 de agosto de 1921, p. 1.

${ }^{14}$ Ibidem. 
las tehuanas, etc. ${ }^{15}$ Hubo un cuarto escenario mayor en importancia y magnitud, que se ubica frente a las cascadas del Bosque; este escenario fue encargado al artista mexicano Adolfo Best Maugard y en él se sucedieron los principales números artísticos, presentando al Ballet Nacional con "la señorita María Cristina Pereda, el señor Armando Pereda y cincuenta bailarinas que deleitarán al público con los bailes mexicanos estilados por el compositor Manuel Castro Padilla y que ejecutará la Orquesta Típica del Centenario bajo la dirección del maestro Miguel Lerdo de Tejada". ${ }^{16}$

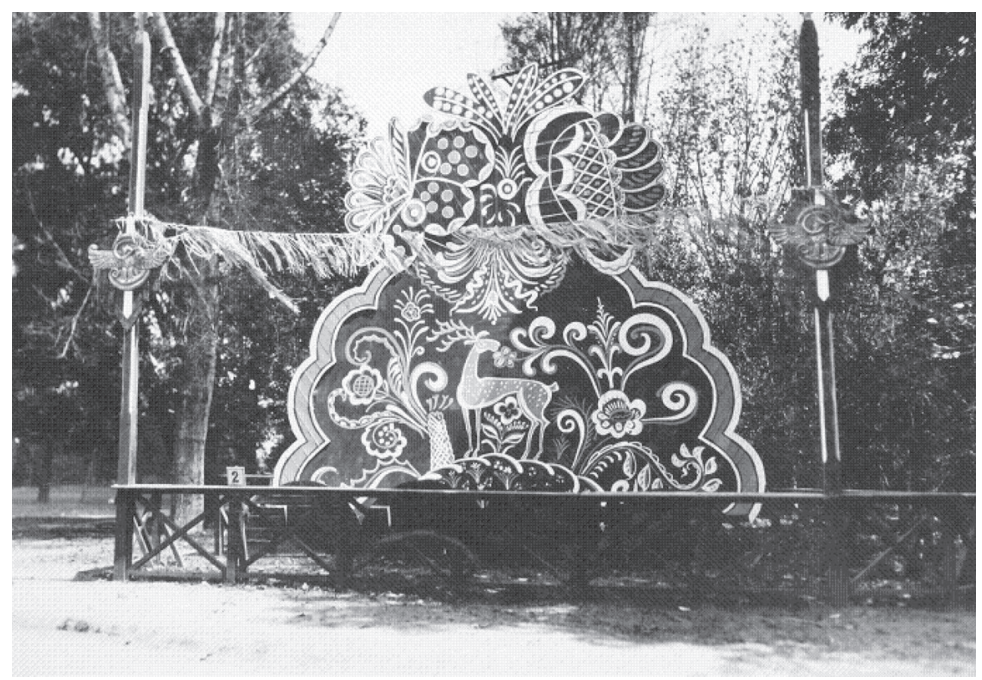

Escenografia de Adolfo Best Maugard para la "Noche Mexicana” en el Bosque de Chapultepec, 1921, Archivo Histórico de la Universidad Nacional Autónoma de México (AHUNAM), Centro de Estudios sobre la Universidad (CESU), Universidad Nacional Autónoma de México, Fondo Martín Luis Guzmán, Álbum fotográfico de Martín Luis Guzmán.

Se dispuso, de igual forma, una simulación del Volcán Popocatépetl del cual salieron una multitud de luces que iluminaba todo el Bosque y que contrastaba con la gran bandera móvil dispuesta para brillar y ser vista desde cualquier punto de Chapultepec. ${ }^{17}$ Mas, pareciera ser que

${ }^{15}$ Véase Manuel Palavicini, "La Noche Mexicana en Chapultepec" en El Universal, 28 de septiembre de 1921, Primera sección, p. 2.

16 "La Noche Mexicana..." en El Universal, 6 de septiembre de 1921, México.

${ }^{17}$ Cabe señalar que se puede encontrar el paralelismo a esta fiesta en el Garden Party organizado en 1910 por la Comisión de festejos del Gobierno de Porfirio Díaz. La fiesta, 
fueron dos espectáculos los que llamaron la atención del público poderosamente. ${ }^{18}$ Por un lado, el bailable calificado por algún crítico como "pictórico"19 de Cristina Pereda en el cual, como se citaba anteriormente, un grupo de cincuenta bailarinas ataviadas con el atuendo tehuano bailaron distintas danzas ${ }^{20}$ de la región oaxaqueña, acompañadas por jicapextles de gran colorido visual. Contrastaba la puesta en escena con la escenografía diseñada por Adolfo Best Maugard, que realizó uno de los trabajos artísticos más bellos del momento siguiendo su método de dibujo ${ }^{21}$ e intermezclándolo con motivos orientalizantes. El decorado presentaba la versión mestiza de la naturaleza mexicana con base en diseños de roleos y estilizaciones gráficas del arte popular que hicieron las delicias del público asistente. Jerónimo Coignard describe así la escena:

¿Recuerdan ustedes cómo es aquella región? Toda suntuosidad de selvas, imponentes y majestuosas como catedrales de verdura; claras reverberaciones solares que pulen y abrillantan el cielo y llenan de espejos rabiosos la tierra; infinitas gradaciones de lo verde, hasta convertir los flancos de las montañas en paletas gigantescas; fuerza, calidez y pasión.

igualmente celebrada en el Bosque de Chapultepec, dada su vasta extensión y por ser signo de patria desde los tiempos independentistas, se desarrolló con un desfile de botes alegóricos de tema mítico que entusiasmó a los asistentes. Al caer la tarde, invadieron al lago los fuegos artificiales y una batalla naval de luces comenzó: dos barcos tras sus murallas lanzaban por sus cañones grandes bocanadas de humo coloreado hasta que el fuerte de "Santa Bárbara" fue destruido por su oponente, deleitando al público con una explosión de fuegos artificiales nuevamente. "El Garden Party en Chapultepec, fue una orgía de luz y de colores" en El Imparcial, 23 de septiembre de 1910, México, p. 1.

${ }^{18}$ El gran éxito de la noche fueron, sin duda alguna, los bailables. A este respecto cabe señalar la importancia del baile en la época, sobre todo, de aquellos sones populares como el Jarabe tapatio, que se convirtió en el espectáculo favorito de nacionales y extraños desde la década de los sesenta del siglo XIX. En el año de 1919 Adolfo Best Maugard y Jaime Martínez del Río propusieron a la bailarina rusa Ana Pavlova la versión clásica del Jarabe en lo que se denominó "Fantasía Mexicana". En aquella ocasión, el ballet se presentó con un vestuario y una escenografía diseñada por Adolfo Best Maugard. Sin duda fue el claro referente para lo que habrían de hacer el Ballet Nacional y la Orquesta Típica en el marco de esta "Noche mexicana".

${ }^{19}$ Jerónimo Coignard, "El valor efectivo del ballet mexicano" en El Universal Ilustrado, 20 de octubre de 1921, año IV, núm. 233, pp. 32-3.

${ }^{20}$ Véase "Otro éxito fue ayer la Noche Mexicana" en El Universal, 29 de septiembre de 1921, Segunda sección, p. 1.

${ }^{21}$ Cfr. Adolfo Best Maugard, Tratado de dibujo. Tradición, resurgimiento y evolución de las artes mexicanas, 1923, México, Secretaría de Educación Pública. 
Sobre este cuadro, las mujeres tienen un aspecto hierático, de soñadora sensualidad. Surgen entre la locura policroma de las flores y de los follajes, con elásticos perfiles de figuras griegas. Envueltas en flotantes vestiduras de delgadas telas, el busto recto y firme, la cabeza erguida y los brazos desplegados del cuerpo, caminan ondulando. Y hay un bello contraste entre la quietud estatuaria del busto, cuya firmeza se adivina bajo el tejido que cubre el brioso desafío de los senos, y la viperina movilidad del cuerpo, a partir de la cintura.

A lo lejos, las tehuanas evocan sobrias y elegantes actitudes de canéforas. Tienen el instinto de la gracia equilibrada, de la sensualidad armónica. Sería imposible imaginarlas en raptos de loca alegría o de voluptuosidad loca. Se supone, viéndolas, que aman, como si realizasen una ceremonia ritual.

Y todo en Tehuantepec obedece al mismo ritmo. La vida está llena de una fuerte, una clara, de una melódica serenidad, que refleja la música, apasionada, graciosa y lánguida. ${ }^{22}$

Esta descripción de Coignard, tan plástica, se vio reflejada en la escenografía de Best. La naturaleza se superpone, la apariencia de selva desordenada ofreció una atmósfera de misterio y exotismo que envolvió al espectador. La influencia en la escena de su Método de Dibujo ${ }^{23}$ era clara y precisa; los elementos básicos propositivos del arte genuinamente mexicano se mezclaban infinitamente tanto en las formas orgánicas como en sus ornamentos, otorgando un paisaje de ensueño. ${ }^{24}$ El Método

${ }^{22}$ Jerónimo Coignard, op. cit.

${ }^{23}$ Adolfo Best Maugard, Método de Dibujo. Tradición, resurgimiento y evolución del arte mexicano, 1923, México, Departamento editorial de la Secretaría de Educación.

${ }^{24}$ Mas no es fortuito encontrar en el universo artístico mexicano de la época el paisaje de Tehuantepec como un paisaje idílico. La región oaxaqueña era vista por los artistas del momento como una expresión del arte mexicano puro; los indígenas -allí- alejados de la gran urbe desarrollaban un tipo de arte purista que de alguna forma entroncaba estilísticamente con el arte de la época precortesiana -sobre todo en lo que a decoración y diseño se refiere- y sus distintas manifestaciones artesanales eran valoradas altamente en la sociedad posrevolucionaria. Por tal motivo, no es fortuito que Sergei Eisenstein, a su llegada a México en el año de 1930 para filmar ¡Qué Viva México! recree cierta parte de la historia en aquel idílico lugar. Para más información véase María de las Nieves Rodríguez y Méndez, "La herencia fotográfica de Tina Modotti y Edward Weston en la obra cinematográfica de Sergei Eisenstein", en Imágenes. Boletín informativo del Instituto de Investigaciones Estéticas, México, Universidad Nacional Autónoma de México, 30 de abril de 2007. Disponible en: http://www.esteticas. unam.mx/boletin_imagenes/anotaciones/ano_rodriguez02.html 
venía a desarrollar toda una idea de construcción gráfica que asentaba las bases de un nuevo sistema de dibujo, sustentado en una gramática visual producida a partir de la combinación de siete trazos básicos del arte prehispánico y popular. Estos elementos tenían su origen en los diseños mostrados en las vasijas prehispánicas, que eran rescatadas tanto por Manuel Gamio como por Franz Boas, de las ruinas de Teotihuacán en el año de 1911; embebidos de la corriente antropológica neoyorquina, contrataron a Best para que fuera dibujando meticulosamente cualquier hallazgo. De esta manera, Best Maugard se dio cuenta de que en todas esas representaciones gráficas había unas normas de factura determinadas y entendió que eran siete los elementos naturales que se combinaban para obtener distintos resultados y bajo cuya mezcla se podían representar gráficamente cualquier forma u ornamento. Este Método parecía haber encontrado la fórmula exacta por la cual se podía crear una representación pura del arte mexicano; de este modo, José Vasconcelos, como Secretario del Ministerio de Educación Pública, decidió editarlo y enseñarlo como una materia más dentro de la carga curricular escolar. Se pretendía recuperar el sentido de lo primitivo por medio del arte popular (las lacas michoacanas o jaliscienses) y lo clásico mediante el arte prehispánico (los hallazgos de las distintas excavaciones de raigambre azteca).

Todo este Método se manifiestó en la escenografía proyectada en el Bosque de Chapultepec: los diseños ondulantes, aparentemente sencillos cobraban fuerza con los vivos colores y la acusada ornamentación. Best, que reconoció al arte como una "necesidad", ${ }^{25}$ fijó sus ojos en el universo del arte popular, el cual magnificó y reinventó en pro de la construcción de un nuevo lenguaje moderno, en consonancia con la vanguardia internacional y así, de modo natural, lo ejecutó con la necesidad no sólo de crear, sino también de hacer patria y de buscar un lenguaje nacional para una fiesta nacionalista.

${ }^{25}$ Manuel Horta, "De charla con Adolfo Best Maugard, un artista que vale mucho" en El Heraldo de México, 18 de junio de 1921, Segunda Sección, p. 1. 
Sus diseños, basados en la naturaleza mexicana, recuperaban el "sabor de la tierra" ${ }^{26}$ y ofrecían de modo estilizado una nueva concepción visual de México, que venía de la mano con la nueva concepción musical y dancística que se estaba ofreciendo en la 'Noche Mexicana”. Así, entendiendo el evento como un todo, se podía comprender no sólo la dimensión estética del Método, sino también la función marcadamente nacionalista que se estaba proyectando desde el gobierno obregonista, anfitrión y creador del evento.

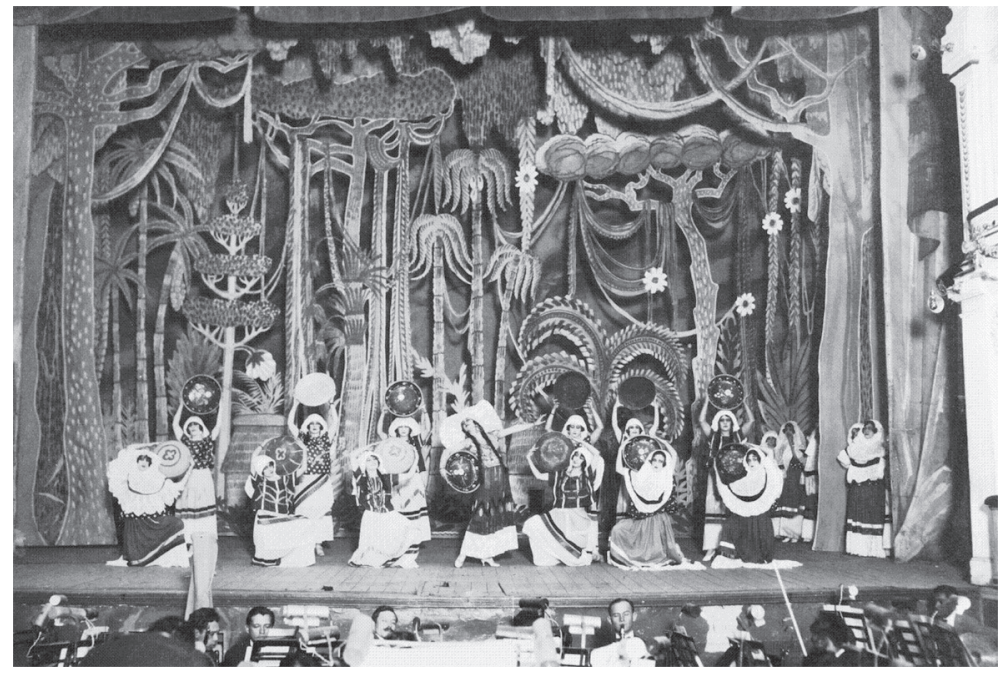

Escenografia de Adolfo Best Maugard para la 'Noche Mexicana'en el Bosque de Chapultepec, 1921, Archivo Histórico de la Universidad Nacional Autónoma de México (AHUNAM), Centro de Estudios sobre la Universidad (CESU), Universidad Nacional Autónoma de México, Fondo Martín Luis Guzmán, Álbum fotográfico de Martín Luis Guzmán.

Y por otro lado, el bailable de las chinas poblanas fue otro de los grandes éxitos de la noche. El ballet, presidido con gran entusiasmo por Ana Pavlova, fue uno de los espectáculos más aclamados de la noche; el deleite de verla bailar el jarabe tapatío perdonó las infidelidades al baile original con que el cuerpo elegantemente quiso ejecutar dicha danza. ${ }^{27}$ Así, "el público y la crítica se rindieron no ante un jarabe acos-

${ }^{26}$ Nicolás Isidro Bardas, "Impresiones sobre la pintura de Adolfo Best Maugard" en El Universal Ilustrado, 27 de octubre de 1921, tomo V, núm. 234, p. 30.

${ }^{27}$ Véase Jerónimo Coignard, "El valor efectivo del ballet mexicano" en El Universal Ilustrado, 20 de octubre de 1921, año IV, núm. 233, pp. 32-3. 
tumbrado a ser bailado a mediados del siglo XIX en las piqueras, en calzón blanco y tosco huarache [¿se refiere al fandango jarocho?], sino a aquella versión en delicada zapatilla de raso color rosa". ${ }^{28}$ Este contexto, frágil y subversivo, sumado a la gran profusión que se tenía de monumentos prehispánicos, tipos populares o paisaje, hizo posible que en fantasías como ésta confluyeran los intereses y la visión nacionalista de una nación plural y multiétnica como México.

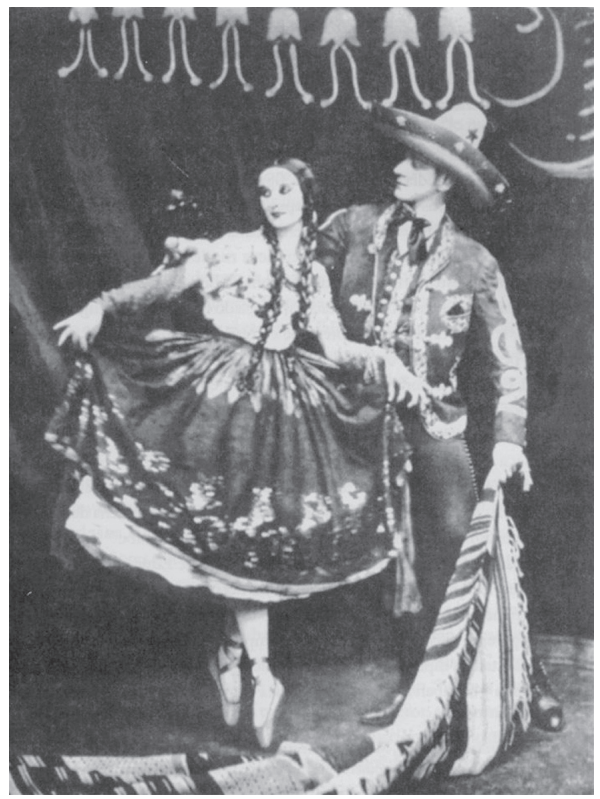

Ana Pavlova y Adolfo Best Maugard, fotografía extraída del libro de Ricardo Pérez Montfort, Estampas de nacionalismo cultural, México, CIESAS.

En esta fotografía se pudo ver a una Ana Pavlova ataviada con su traje de china poblana; sin embargo, no era una imagen popular puesto que su peinado y sus zapatillas daban una imagen idealizada de las chinas que se habían difundido ampliamente en las estampas del siglo XIX. En ellas, las chinas mostraban sus encantos sin pudores ni recato, se declaraban afectas a la diversión, pues bailes y fiestas eran su mejor

${ }^{28}$ Josefina Lavalle, "El Jarabe como género bailable en los escenarios teatrales del siglo XIX y XX”, en Signos. El arte y la investigación, 1988, México, Instituto Nacional de Bellas Artes, p. 167. 
guía y acompañante. El traje, que lucían de modo espectacular, estaba conformado por una camisa blanca ricamente adornada y atada a medio brazo, que dejaba advertir la forma del seno - puesto que no usaba corsé- y se entallaba en la cinturilla delgada de la cual nacía una falda amplia y bordada, rematada con encaje de bolillo -enchilado- de la cual asomaba su diminuto pie. Iba, generalmente, envuelta en su rebozo de color y adornada con trenzas en el pelo y collares de monedas de oro. ${ }^{29}$ La tradición apunta a que el atavío era originario de España, recuperado de una herencia gitana ya amestizada de modo autóctono, puesto que hubo diferentes tipos de chinas según la región del país. Encontramos, así, a la Tapatía de Jalisco, la China de México, la Jarocha de Veracruz o la Clanizata de Oaxaca; todas con sus variantes específicas. De esta forma, lo mexicano podía transfigurarse igualmente en la música y en la danza mediante sones como el Jarabe y de bailadores típicos que reunían las cualidades determinadas de sentimiento y emoción necesarias para interpretar ese "costumbrismo sonoro" 30 que fue considerado fundamental para el desarrollo nacionalista del país ya en el siglo XX. A este respecto, cabe mencionar que quizás, dada la importancia del evento, Adolfo Best Maugard rescató al personaje histórico y lo idealizó en pro de la construcción de un estereotipo de gran belleza formal.

Por todo esto, la "Noche Mexicana" fue un éxito rotundo y uno de los acontecimientos más importantes de los festejos centenarios. La celebración se repitió nuevamente el 28 de septiembre -dos días después del primero- con todos sus detalles, poniéndose a la venta entradas en las taquillas de los Teatros Arbeu, Iris, Principal y en el despacho de la Ópera del Centenario, asequibles por la módica cantidad de cinco pesos. De este modo, lograban acercar esta fiesta al pueblo llano, ya que la primera se celebró para los distintos cargos gubernamentales, el Honorable Cuerpo Diplomático, funcionarios, representantes consulares, fami-

${ }^{29}$ Apud Ricardo Pérez Montfort, Estampas de nacionalismo cultural, México, CIESAS.

${ }^{30}$ Yolanda Moreno Rivas, Rostros del nacionalismo en la música mexicana. Un ensayo de interpretación, 1995, México, Universidad Nacional Autónoma de México, Escuela Nacional de Música, p. 79. 
lias distinguidas e invitados de honor -casi doscientas mil personas- ${ }^{31}$ para que luego, el pueblo más acomodado, tuviera la oportunidad de disfrutar también del mismo.

De cualquier modo, esta fiesta constituyó - como el resto de los festejos centenarios- en su momento y en la actualidad, a ciento dos años de su ejecución, un verdadero testimonio de la celebración y fue, si duda alguna, un testigo impávido de la construcción nacionalista en México, debido en mucho al apoyo y al énfasis dado por los gobiernos posrevolucionarios y, muy especialmente, por el de Álvaro Obregón. ${ }^{32}$

${ }^{31}$ Manuel Palavicini, op. cit.

${ }^{32}$ Es oportuno transcribir, a modo de cierre, una pequeña carta realizada por la redacción de la revista semanal mexicana El Universal Ilustrado que, de forma jocosa, alude a la carta escrita por un indígena que se ha traslado a la capital de la República de modo ex profeso para asistir a los festejos patrios, los cuales narra, con gran acierto, a su pequeña hija. Este versillo constituye el mejor resumen de una realidad que fue común tanto para el centenario de 1910 como para el de 1921:

Mi cuca:/De saber te perdiste/lo ques cajeta de Celaya... y fina;/no ha habido fiesta en donde no me enviten,/ menos ca Juana, pues por más que quise,/como di la levita/a planchar y es l'única ... iqué quieres!

Me quedé en el Hotel con Casimira. En tos periódicos/que te enviao/van tiatros, toros,/desfiles y carros./;Y de los carros, uno! jes la sangre que quita!/Tú bien sabes, mi Cuca, que naci en Panzacola;/soy indio lustradito como tú y esta sola/ilusión me condujo a ver la India Bonita. Entérate y verás cómo/hice mi pior disparate/pues verla iy trair zoyate/ni guayabera! Ni al lomo

ir di un penco pa rayarlo/y echarle a grito tendido/;Bien haiga lo bien ... nacido/que ni trabajo da criarlo! No te enceles, Cuca,/no te enceles, hija, /isi sal cabo tú eres/mi india bonita!/No grité, ni nada,/ me estorbaba todo:/cubeta, los guantes,/el paragua, el choclo... ¡Malaigan las prendas/que la moda trajo! Ansi ni es uno indio/ni civilizado!/Me reduje a verla/radiante de vida.../-no te enceles, Cuca,/no te enceles, hija-/iSi pa mí tú eres/la india bonita! No quiero, por más que quiero, recordar el hervidero de la Nochi Mexicana,/pues por culpa de esa broza mandé planchar mi alevosaly no jui en casa de Juana./Y repitieron la Nochi/Mexicana con derrochi de todavía más ecsesos.../No juí por tonto o por vivo y por este otro motivo:/que costaba cinco pesos.

Después el desfile, los charros, clarines.../iy yo en las tribunas! iy aquellos botines/mi apretaban todo lo que no imagines!/;con decir que quise verlo en calcetines!

Y lo que falta del mes/te lo platico en barbecho: Ique hasta los niños de pecho/tuvieron fiesta; después los niños pobres, los nones, /los del hambre brava, el susto,/tuvieron su hora de gusto/en cochis, autos, camiones.

Y hasta l'otra, Cuquita de mis entretelas;/tu fiel hasta el joyo".

Citado en "Ecos del Centenario" en El Universal Ilustrado, 13 de octubre de 1921, México, tomo V, núm. 232, p. 6. 
CITAM Derechos Reservados.

La reproducción total o parcial de este artículo se podrá hacer si el ITAM otorga la autorización previamente por escrito. 